\title{
A conceptual framework for multi-regional climate change assessments for international market systems with long-term investments
}

\author{
Julie A. Winkler · Suzanne Thornsbury • Marco Artavia • Frank-M. Chmielewski • \\ Dieter Kirschke · Sangjun Lee • Malgorzata Liszewska • Scott Loveridge • \\ Pang-Ning Tan • Sharon Zhong • Jeffrey A. Andresen • J. Roy Black • \\ Robert Kurlus • Denys Nizalov • Nicole Olynk • Zbigniew Ustrnul • \\ Costanza Zavalloni · Jeanne M. Bisanz • Géza Bujdosó • Lesley Fusina • \\ Yvonne Henniges • Peter Hilsendegen · Katarzyna Lar · Lukasz Malarzewski • \\ Thordis Moeller • Roman Murmylo • Tadeusz Niedzwiedz • Olena Nizalova • \\ Haryono Prawiranata • Nikki Rothwell · Jenni van Ravensway · Harald von Witzke • \\ Mollie Woods
}

Received: 17 January 2008 / Accepted: 30 October 2009 / Published online: 14 January 2010

(C) The Author(s) 2009. This article is published with open access at Springerlink.com

\begin{abstract}
A conceptual framework for climate change assessments of international market systems that involve long-term investments is proposed. The framework is a hybrid of dynamic and static modeling. Dynamic modeling is used for those system components for which temporally continuous modeling is possible, while fixed time slices are used for other system components where it can be assumed that underlying assumptions are held constant within the time slices but allowed to vary between slices. An important component of the framework is the assessment of the "metauncertainty" arising from the structural uncertainties of a linked sequence of
\end{abstract}

\footnotetext{
J. A. Winkler $(\varangle)$ · S. Zhong · J. A. Andresen · J. M. Bisanz · L. Fusina ·

H. Prawiranata $\cdot$ J. van Ravensway

Department of Geography, Michigan State University,

118 Geography Building, East Lansing, MI 48824-1117, USA

e-mail: winkler@msu.edu

S. Thornsbury $\cdot$ S. Lee $\cdot$ S. Loveridge $\cdot$ J. R. Black $\cdot$ N. Olynk $\cdot$ M. Woods

Department of Agricultural, Food, and Resource Economics, Michigan Sate University,

East Lansing, MI 48824, USA

M. Artavia · D. Kirschke

Department of Agricultural Economics and Policy, Humboldt-University, Berlin, Germany

F.-M. Chmielewski · Y. Henniges

Faculty of Agriculture and Horticulture, Humboldt-University, Berlin, Germany
}

M. Liszewska

Interdisciplinary Centre for Mathematical and Computational Modelling,

University of Warsaw, Warsaw, Poland 
climate, production, trade and decision-making models. The impetus for proposing the framework is the paucity of industry-wide assessments for market systems with multiple production regions and long-term capital investments that are vulnerable to climate variations and change, especially climate extremes. The proposed framework is pragmatic, eschewing the ideal for the tractable. Even so, numerous implementation challenges are expected, which are illustrated using an example industry. The conceptual framework is offered as a starting point for further discussions of strategies and approaches for climate change impact, vulnerability and adaptation assessments for international market systems.

\section{Introduction}

Assessing the vulnerability of human and natural systems to climate variability and change, the possible impacts of a changing climate on these systems, and the potential for adaptation is a challenging undertaking, in part because assessment methods remain incomplete. As noted by previous authors (e.g., Füssel 2007; Yohe and Tirpak 2008), improved and expanded approaches and frameworks are needed to address the wide range of goals and objectives of climate change assessments and to more effectively inform decision making and policy formulation.

P.-N. Tan

Department of Computer Science and Engineering, Michigan State University, East Lansing, MI 48824, USA

R. Kurlus · K. Lar

Department of Pomology, Poznan University of Life Sciences, Poznan, Poland

D. Nizalov $\cdot$ R. Murmylo $\cdot$ O. Nizalova

Kyiv Economics Institute, Kyiv School of Economics, Kyiv, Ukraine

Z. Ustrnul

Department of Climatology, Jagiellonian University, Kraków, Poland

C. Zavalloni

Department of Agriculture and Environmental Sciences, University of Udine, Udine, Italy

G. Bujdosó

Research Institute for Fruit Growing and Ornamentals, Budapest, Hungary

P. Hilsendegen

DLR Rheinpfalz, Oppenheim, Germany

L. Malarzewski · T. Niedzwiedz

Department of Climatology, University of Silesia, Sosnowiec, Poland

T. Moeller $\cdot$ H. von Witzke

Department of International Agricultural Trade and Development, Humboldt-University, Berlin, Germany

N. Rothwell

Northwest Horticultural Research Station, Michigan State University, 6686 S. Center Highway, Traverse City, MI 49684, USA 
The most recent report of the Intergovernmental Panel on Climate Change (IPCC) Working Group II outlines several approaches to assessments of climate change impact, adaptation and vulnerability (CCIAV) (Carter et al. 2007). The vast majority of previous CCIAV studies fall into what the IPCC authors refer to simply as "impact assessments". Carter et al. (2007) consider these studies to be "top down" approaches, as usually local or regional climate scenarios are developed from projections of global climate models (GCMs), ${ }^{1}$ and the climate scenarios are then applied to evaluate how a local/regional process or system may be impacted by a perturbed climate. On the other hand, "vulnerability assessments" and "adaptation assessments" are considered by the IPCC authors to be primarily "bottom up" approaches that scale from the local to the regional or even to the global. Vulnerability assessments consider the potential exposure of a local/regional human or natural system to climate change and explore ways to reduce vulnerability, whereas adaptation assessments investigate the adaptive capacity and potential adaptation strategies of a local/regional system (Carter et al. 2007). In contrast, the fourth approach outlined by Carter et al. (2007), referred to as an "integrated assessment", emphasizes interactions and feedbacks between multiple drivers, is typically characterized by a global rather than local or regional viewpoint, and frequently focuses on a sector or even multiple sectors of the economy rather than an individual system.

Not all assessment requirements fit neatly into these four approaches, however. In particular, there is a growing need for assessment strategies that fall within the "gap" between impact assessments and integrated assessments. Strategies are needed for climate change assessments that go beyond the local or regional scale of a "traditional" impact assessment, yet do not require the typical sectoral or cross-sectoral emphasis of an integrated assessment. For example, a climate change assessment focused on a specific industry (i.e., a sub-sector) that has international markets requires a much broader spatial perspective than the typical "global to local" assessment, but usually does not require the comprehensive, although often "broad brush", approach of an integrated assessment. International market systems, by definition, are characterized by multiple production regions that are distributed worldwide and likely to be differentially impacted by climate change. In addition, for many industries and market systems, especially those with long-term climatedependent investments, temporal dynamics need to be incorporated into the assessment process, including changing patterns of international trade, consumption and production along with evolving adaptation strategies by industry stakeholder groups. Given these demanding requirements of an industry-wide climate change assessment, it is not surprising that few, if any, sub-sectoral assessments have been completed to date.

Our goal is to provide a potential framework and strategy for conducting subsectoral, multiregional climate change assessments. In particular, the framework is intended for industries with international markets, long-term capital investment decisions, limited adaptation options, and sensitive to unusual or intense weather and climate events or conditions. The challenges of undertaking such an assessment are

\footnotetext{
${ }^{1}$ Historically, "GCM" has referred to General Circulation Models. More recently, the phrase "Global Climate Models" has gained popularity. This term better represents the coupled nature of most climate models.
} 
outlined, and tractable but meaningful methods for implementing the framework are proposed. We stop short of providing an actual assessment. Rather, the framework outlined here is intended as a "jumping off point" for further discussion and refinement of methods and represents an initial step to address an important gap in the CCIAV literature. The proposed framework is the outgrowth of a pilot study to explicitly investigate potential CCIAV approaches for international market systems.

An example industry from agriculture is utilized to help illustrate the proposed framework and potential approaches for implementing the framework. The selected industry, tart (sour) cherry production, is highly sensitive to climate extremes and threshold events, particularly to extended springtime warm periods followed by cold temperatures that cause buds to lose hardiness and become susceptible to frost damage. In addition, the tart cherry industry reflects the challenges encountered by, and limited adaptation strategies of, any industry that has long planning horizons and long-term investments. Tart cherry orchards have life cycles of 20-30 years with limited adaptation options for growers and other industry participants. The tart cherry industry also is currently undergoing a substantial evolution in terms of changing major production areas with large potential regional and international shifts of production and international trade.

Although we use a specific industry as an illustration, the proposed framework is intended for any climate sensitive industry or investment class requiring long-term capital investment decisions. Tourism infrastructure (e.g., theme parks, ski resorts, snowmobile trails, and beach front hotels), which is sensitive to changes in the frequency and intensity of weather and climate events such as warm winters with little snowfall or devastating tropical cyclones (e.g., Scott et al. 2006; Becken and Hay 2007), is one example for which the proposed framework would be suitable. Another example is the construction of off-shore oil platforms (e.g., Agasse 2007); for higher latitude locations changing patterns in the frequency and strength of extratropical cyclones are a concern for investment decisions, whereas tropical cyclone frequency and/or intensity need to be considered for tropical and subtropical locations. Mining operations at high latitude locations that utilize ice roads for transporting supplies or shipping product also are sensitive to a changing climate that can make the roads unsafe, requiring more costly air transport (e.g., Ford et al. 2009), and potentially reducing profitability compared to other mining locations. Plant locations for manufacturing products whose demand is weather and climate sensitive (e.g., boats, snowmobiles) provide yet another example of industries which require an alternative assessment approach (e.g., McBoyle et al. 2007).

\section{Dynamic versus static modeling: a proposed hybrid framework}

An ideal approach to a climate change assessment is a complex model running continuously in time that simulates the different components of the system and allows for feedbacks between system components. This type of dynamic modeling approach often is advocated for integrated assessments (e.g., Van Asselt and Rotmans 2002), although, as pointed out by Schneider and Lane (2005), current integrated assessment models are not fully integrative across all aspects of a system and have relatively simple characterizations for some if not all of the system components. For the most part, integrated assessment models, such as the well known DICE 


\section{Impact Assessments}

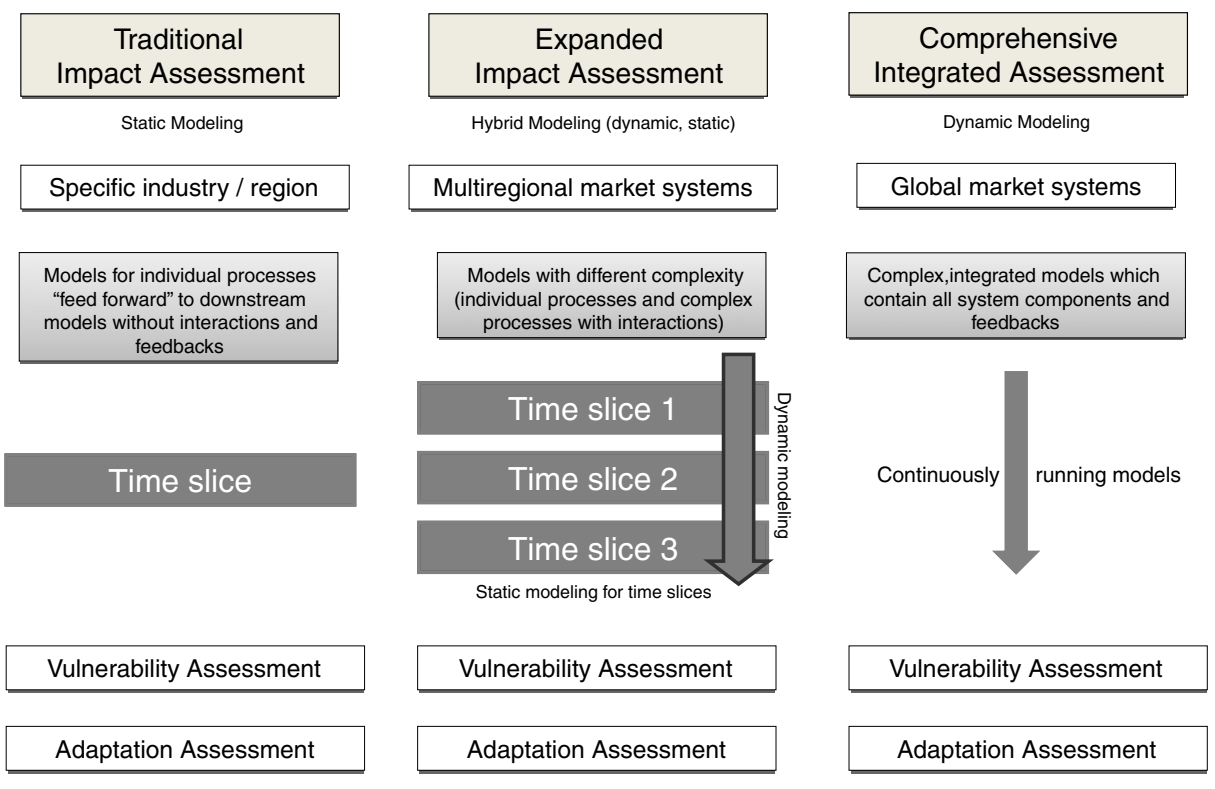

Fig. 1 Comparison of the "expanded" to traditional and integrated approaches of climate change assessments. See Fig. 2 for a more detailed view of the within and between time slice modeling

(Dynamic Integrated model of Climate and the Economy) model (Nordhaus 1994), have been used to assess the influence of potential mitigation policies on global greenhouse gas concentrations. More typically, climate change impact analyses, especially those for a specific location and activity or system, have used a "linked" or "feed forward" approach where output from separate, often complex, models for each of the different system components is fed into the next "downstream" model. ${ }^{2}$ Here, complexity is retained for the individual system components but interactions among components are sacrificed. Also, these types of analyses generally have employed a more static approach, preferring to investigate the potential impacts of future climate for a prescribed, discrete time period rather than the evolution of the impacts through time.

A hybrid approach that employs both dynamic modeling and multiple fixed time slices is a potential framework for implementing a climate change impact analysis

\footnotetext{
${ }^{2}$ Some confusion exists in the literature in regard to the terms "integrated assessment" and "climate change impact assessment". We are reserving the use of "integrated assessment" for studies that employ integrated assessment models that allow for feedbacks among system components and are referring to all other studies as "climate change impact assessments". Other authors have used the term "integrated assessment" more broadly to imply any impact assessment that includes physical, economic and social aspects of a system whether or not feedbacks are included. An example is the study of Fischer et al. (2005). Although they label their study an "integrated assessment", it is in effect an end-to-end assessment with climate scenarios fed into a global agro-ecological zone model, and the output from the agricultural model used as input to a world trade model, with no feedbacks allowed between model components.
} 
for market systems with long-term investments (Fig. 1). This "expanded" framework allows for continuous, evolving projections of those system components for which this is possible and uses a time slice approach for those components where dynamic modeling is not feasible. For most impact analyses, continuous projections of a future climate can be obtained from climate model simulations, although these models are not entirely interactive as the temporal evolution results primarily from changes in greenhouse gases, while other dynamic interactions, such as change in land cover, rarely are included. Estimation of the weather and climate impact on an industry's production potential may also be approachable with dynamic modeling, depending on the industry. On the other hand, dynamic, continuous modeling is much more difficult for economic components of the system. Although economic activities evolve over time, the development of fully dynamic models is currently not tractable for most applied problems. Dynamic models are either overly abstract or the modeling effort requires abundant resources usually not available for climate change impact assessments (e.g., Sohngen et al. 2001).

The length of the time slice and the separation between time slices is industry specific and reflects, among other factors, the expected degree of variability in climate, production, and the lifetime of an investment. For those components of a system where dynamic modeling is possible, the time slice represents simply a segment of the output, still allowing for continued change within the time slice. For the example industry, climate projections would be considered continuous in time, and projections for the defined time slices would be extracted from the projected time series (Fig. 2). Production potential, or projected yield in the case of the example

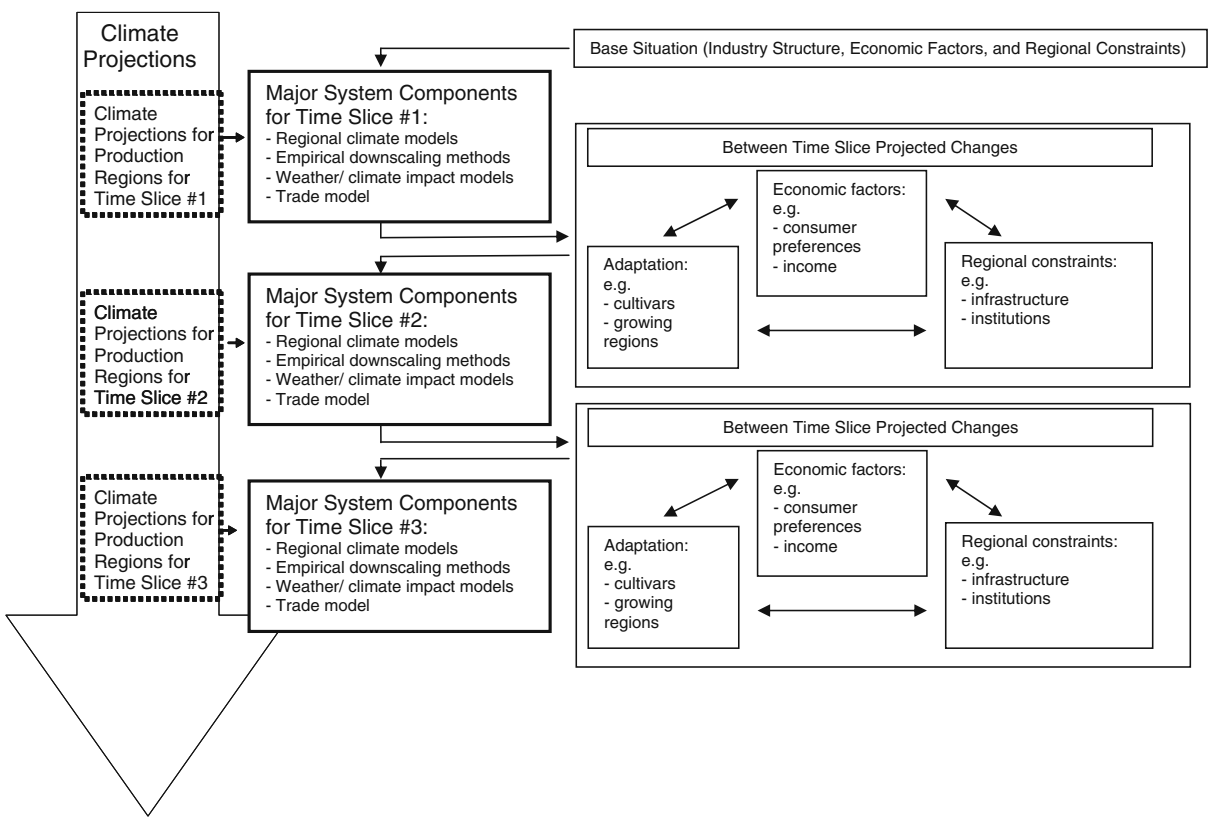

Fig. 2 Schematic of a hybrid dynamic-static approach to climate change impact assessments for market systems with long-term investments, with particular reference to the tart cherry industry 
industry, is "quasi continuous" in that the projected yield reflects the evolving climate conditions during the time slice but assumes fixed technology and cultural practices. Other system components for the example industry are considered static in the sense that the underlying assumptions do not change within a time slice although interactions among components can occur within a time slice.

The proposed framework is not without challenges for implementation. A key challenge is the identification of the important system components that need to be modeled for each time slice and the development of models that sufficiently represent these components. For some industries, the suite of components may remain constant from one time slice to another, whereas for others changes in underlying assumptions may result in changes in the number and type of components that need to be considered for succeeding time slices. Another challenge is the identification of which economic factors are internal and external to the industry. For example, in the tart cherry industry internal industry-specific factors for which between time slice scenarios are required include changes in cultivar and growing regions. External, economic factors with impacts on the industry include shifting consumer preferences, economic growth (i.e., gross domestic product), and income, among others. A related issue is definition of endogenous versus exogenous variables for each time slice. For early time slices many variables are likely to be exogenous due to long-term industry investments, whereas with time, more variables become endogenous, or in other words, within the investor's control. A further challenge is to evaluate differences in the sensitivity of the industry to differences in climate within and between the multiple production regions. Still another challenge is to incorporate adaptation into the assessment, which often occurs at the level of the individual investor. These challenges are discussed further below, again in the context of the example industry.

\section{Defining system components for a time slice}

Linked models are used in the proposed framework to assess, for each time slice, the potential impact of a changing climate on the market system. Thus, an initial step is to identify the major system components for a particular market system, keeping in mind that the number of components depends on the complexity of the market system and may change with time. The chain of linked models is likely to include climate projections, models of the dependency of production on weather and climate, and one or more models of flows, trade, and decision making including the evaluation of adaptation options (Fig. 2). Selection and/or development of the individual models is an interdependent activity as the level of detail required by "downstream" models informs the scale considerations and development of "upstream" models. The models of the weather/climate dependency of a market system are of central importance in the chain, as the output of these models is a joint probability distribution of production across regions which, in turn, drives the downstream, broadly defined, economic models. In the subsections below, we discuss the types of linked models that would appear in most multi-regional impact assessments for international market systems with long-term investments. Using the tart cherry industry as an example, methods and challenges of developing and linking the models are discussed and illustrated, including specifying the changes with time in exogenous and endogenous variables. 
3.1 Modeling the weather and climate dependency of an industry

For each time slice, an industry's dependency on weather and climate must be identified and quantified. Although at first glance this step may appear relatively straightforward, the experience of past impact assessments suggests otherwise. Some earlier assessments were able to take advantage of previously-developed processbased models; for example, the Decision Support System for Agrotechnology Transfer (DSSAT) model ensemble (Jones et al. 2003) has been used in a number of assessments for agriculture ranging from agronomic productivity (e.g., Tsvetsinskaya et al. 2003; Brassard and Singh 2007) to crop management (e.g., Eitzinger et al. 2003) to soil fertility (e.g., Gijsman et al. 2002). Process-based models offer a theoretical advantage in climate change assessments as they allow simulation over a wide range of conditions, even potentially including those outside the range used in the original model development. Unfortunately, for many applications process models do not currently exist and developing the models becomes a part of the assessment process (e.g., Lobell et al. 2006). Typically, the models are fully or partially empirical in nature and often are "tuned" for a specific location. The local character of the models is an issue for impact assessments for industries with worldwide production regions, as the type and relative contribution of factors influencing production may differ regionally and hence the model may not perform well outside of the region for which it was developed. Furthermore, the available data for model development and validation usually varies regionally.

The tart cherry industry highlights these challenges. Process models (i.e., crop models) currently are not available for tart cherries, or for that matter for most specialized agricultural crops. Responses of specialized agricultural crops to environmental conditions depend greatly on the rate or stage of development. For example, development of a phenology (and ultimately, a yield) model was an initial, time consuming step of an earlier, region-specific climate change impact assessment for tart cherries known as the Pileus Project (Zavalloni et al. 2006a, b, 2008). Phenological observations were extremely difficult to obtain, and the spatial resolution of the yield information (United States county level) presented considerable scale and aggregation challenges. Temporal data resolution also was an important consideration, as major reductions in yield due to extreme events such as subfreezing temperatures or hailstorms can take place in a matter of hours. The daily time step used in the earlier assessment reflects a compromise between the desired subdaily resolution and the availability and limitation of historical and projected future climate data. Our earlier work also illustrates the potential regional specificity of models used in assessment studies, particularly empirically-derived models. For example, the yield function derived by Zavalloni et al. (2008) for the major tart cherry growing regions in the northwestern and west-central Lower Peninsula of Michigan (USA) did not perform as well in the much more diverse cherry-producing regions in the southwestern corner of the state (C. Zavalloni, personal communication). However, it is difficult to separate out whether the differences in model performance were due to limitations of the model itself or due to inhomogeneities and systematic errors in the climate data for the observing stations used to initially derive the model and for the stations where the model was later applied. Thus, our experience suggests that detailed model validation for individual regions, along with careful data quality controls, is needed for impact assessments of industries with global production regions. This is also true 
to some extent with process-based models. For example, process-based crop models require that cultivar, soil, crop management, and other system characteristics be explicitly specified for the simulation to realistically represent conditions in a given area of interest (e.g., Andresen et al. 2001).

The tart cherry example also illustrates that modeling an industry's weather/ climate dependency may be approached from different avenues. Above we have emphasized what we loosely consider the "production function" approach where weather and climate variables are used to simulate production distribution (yield for the example industry). However, hedonic modeling is an alternative approach that has been used in several assessments of climate change impact on agriculture (e.g., Mendelsohn et al. 1994; Deschênes and Greenstone 2007; Schlenker et al. 2005 , 2007). In hedonic modeling, the impact of climate on land prices rather than production typically is modeled. Arguments can be made in support of either a production function or a hedonic approach to an assessment, but, whatever the approach that is used, its limitations must be acknowledged and considered when interpreting the assessment findings.

Another challenge is whether a model developed based on our current understanding of the weather and climate dependency of an industry is applicable to future periods, as important within region or even individual adaptations to climate change occur between time slices. For the example industry, a potential adaptation strategy is to change cultivars. At the present time, one cultivar, "Montmorency", is grown in United States tart cherry production areas and the cultivar "Morello" is grown in major European production areas. Plant breeding efforts are in place in both Europe and the United States to develop cultivars that are less sensitive to frost damage, for example with different heat accumulation requirements or different overwinter dormancy requirements. In this case, we expect lagged improvements in resistance to late frost (the primary climatic variable in determining yield potential), reducing the weather-related variability in yields. Also, current production regions may no longer be profitable in a changed climate and may be replaced. Therefore, potential new production regions also must be assessed in light of projected changes in climate and possible future adaptations, and weather/climate dependency models will need to be developed and/or validated for these new regions.

\subsection{Scenarios of climate variability and change for individual production regions}

The starting point for most climate change impact assessments is an individual climate scenario or a suite of such scenarios. A climate scenario frequently is defined as a "plausible and often simplified representation of the future climate, based on an internally consistent set of climatological relationships" (IPCC 2001, p. 993). Numerous studies on climate scenario development have been published. For the most part, these studies are limited to one country, (e.g., Hulme et al. 2002; MacCracken et al. 2003; Arnell et al. 2005), a particular region within a country (e.g., Leung et al. 2004), or individual sites within a region (e.g., Winkler et al. 2002, 2010). The framework proposed here, which requires detailed climate scenarios for locations on multiple continents, presents a new challenge in scenario development and use. The limitations and weaknesses of scenarios, including compromises made, are accentuated when an assessment is required for multiple worldwide locations. 
This type of application necessitates modified or even new approaches to scenario construction.

The types of markets systems that are considered here are extremely sensitive to unusual or intense weather and climate events or conditions that are often localized and of short duration. Thus, climate scenarios with fine (daily or even subdaily) temporal scales and at local spatial scales are required. The primary tool for developing climate change scenarios is one or more GCM simulations driven by different greenhouse gas emissions scenarios. In the proposed framework, coarse scale GCM simulations ( $\sim 150-300 \mathrm{~km}$ spacing) are sufficient for the between time slice periods. Within a time slice GCM output will need to be "downscaled" to the local and/or regional scale. Downscaling methods are usually categorized into two classes referred to as "dynamic" and "empirical" (see Wilby et al. 2004 for a review of downscaling methods). Dynamic downscaling utilizes climate projections from GCMs as initial and boundary conditions for a regional climate model (RCM) that runs at a much finer $(10-50 \mathrm{~km})$ scale. RCMs capture the geographic details of a region (e.g., topography, land cover) and climate phenomena (e.g., regional-scale airflow) associated with these details which are unresolved by the coarse grid GCMs. In contrast, empirical downscaling methods can be used to construct scenarios at a range of spatial scales, including local (e.g., orchard) scale. These methods use statistical or machine learning techniques to derive a relationship between largescale atmospheric variables (e.g., upper-level airflow, vorticity, circulation modes), and local scale predictands (e.g., temperature, precipitation).

A simple choice between a dynamic or empirical downscaling approach for an industry-wide assessment is not possible. The current resolution of RCMs (10$50 \mathrm{~km}$ ), although much finer than that of GCMs, remains too coarse for most applications, including the example tart cherry industry. Even if RCM output were to become available at very fine horizontal spatial scales, empirical methods may still be necessary to "debias" the output, or in other words, to adjust for the propagation of error originating from the driving GCM and for error introduced by the RCM itself. Given these constraints, we advocate that multi-region, multilocation assessments employ a "combined" downscaling approach that uses empirical functions to translate the "intermediate" scale output from RCMs to the local scale. The empirical approach guarantees that scenarios at a local scale are available, and starting with the finer-scale RCM output, rather than coarse-scale GCM output, increases the likelihood that the impact of regional-scale circulation on the local climate parameters is captured. Empirically downscaling from the RCM rather than GCM output will also improve the physical consistency of the resulting scenarios. In addition, including an empirical step in the downscaling procedures provides an opportunity to adjust for biases.

Several challenges when implementing a combined downscaling approach can be expected. One challenge is that a calibration data set with a spatial resolution similar to that of RCM output is not easily available for many parts of the world. One exception is North America for which a regional reanalysis with a grid resolution of $32 \mathrm{~km}$ was recently released (Mesinger et al. 2006). Another difficulty is capturing climatic extremes for those market systems, such as the tart cherry industry, that are very sensitive to extremes. Most empirical downscaling methods are biased toward capturing dominant signals of the data and consequently are not effective at projecting extremes. Changes in extremes also are not well modeled in GCMs or 
RCMs so methods need to be developed to deduce them based on relationships with other variables that are produced by GCMs or RCMs, reanalyses, and observations.

Another issue is whether to perform RCM runs specific to the assessment or to utilize existing RCM output for the regions of interest. Output from RCM runs have not been as widely available as GCM output, but several recent programs, such as NARCCAP (North American Regional Climate Change Assessment Program; http://www.narccap.ucar.edu/), PRUDENCE (Prediction of Regional scenarios and Uncertainties for Defining EuropeaN Climate change risks and Effects; http:// prudence.dmi.dk/), ENSEMBLES (http://www.cru.uea.ac.uk/projects/ensembles/ ScenariosPortal/index.htm), and CECILIA (Central and Eastern Europe Climate Change Impact and Vulnerability Assessment; http://www.cecilia-eu.org/index.htm), are making multiple RCM downscaled regional climate change scenarios readily available. Utilizing these RCM output allows for more effort to be focused on establishing empirical-statistical relationships between RCM-resolved climate variables and local variables. On the other hand, performing RCM runs specific to the assessment, if resources and time permit, allows more control on what underlying emissions scenarios and $\operatorname{GCM}(\mathrm{s})$ to use in the scenario construction. If already available RCM simulations are employed, it is unlikely that a consistent scenario suite (i.e., same driving GCMs and greenhouse emissions scenarios for each location) will be available, even if the RCM is permitted to vary by location. This is certainly the case today for the existing sets of RCM runs from the major modeling experiments mentioned above, as illustrated by the lack of overlap between time periods for which future simulations are available for Europe and the United States (Fig. 3).

Finally, landscape variability may need to be "re-introduced" into the downscaled scenarios. The downscaling that we are advocating focuses on the local scale, and scenarios would be available for point locations near production areas for which climate data and production data are available. These locations are likely to be distributed unevenly in space. For some industries, microclimate associated with local topographic and land use variations can have a relatively large impact on production. That is the case for the example industry, where freeze risk is greater in landscape depressions (i.e., valleys) than along the sides and tops of hills where orchards are usually located. Introducing landscape variability into climate change scenarios

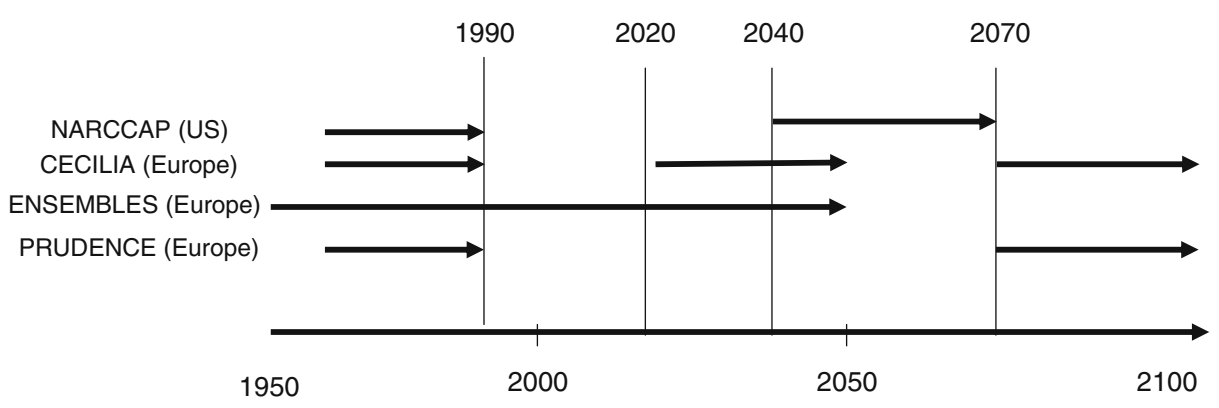

Fig. 3 Time periods for which simulations are available for Europe and the United States from major regional climate modeling experiments 
is challenging. For the tart cherry industry, high resolution satellite observations (for example, MODIS temperature estimates) are one potential resource, when compared to observed temperatures at point locations, for developing landscapescale transfer functions of surface temperature.

\subsection{Economic modeling of supply, demand and trade}

Trade links markets between production regions both within a country and internationally. A model of global trade thus becomes an important component of assessing impacts of climate change. A vast literature exists for both the theory and applications of trade models (see for example; Anania 2001; Francois and Reinert 1997; Van Tongeren and Van Meijl 1999; Jechlitschka et al. 2007; von Witzke et al. 2008). Trade models incorporate supply and demand in multiple regions and generate regional production levels and trade flows between regions in a given period of time.

Alternative approaches exist on how to incorporate international market interaction including partial equilibrium and computable general equilibrium models. For reasons of tractability, partial equilibrium models are typically used for sub-sectoral studies. A partial equilibrium model assumes that shocks to the industry do not feed back through the system to change macro variables such as inflation or the exchange rate (e.g., Reilly and Hohman 1993). For the tart cherry industry, a partial equilibrium model is a reasonable choice as trade for the product is confined to a few countries. Furthermore, the partial equilibrium approach lends itself to focusing on simulation of the climate effect, while holding many macro-level and production technology variables fixed within a time slice.

A standard partial equilibrium two-region trade model is depicted in Fig. 4. The importing country is depicted on the left and the exporting country on the right with initial conditions shown in the supply and demand functions $\mathrm{S}$ and D in each region. Without trade each country would produce and consume tart cherries at the intersection of these two functions within their own region. Once trade is allowed, product moves between regions, depicted as the world market in the center panel

Importing country

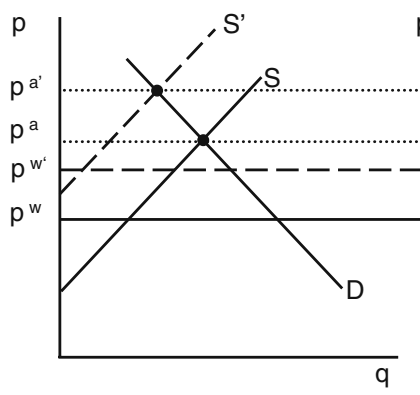

World market

$\mathrm{p}$

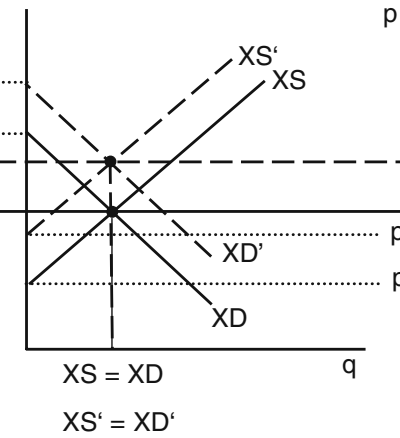

Exporting country

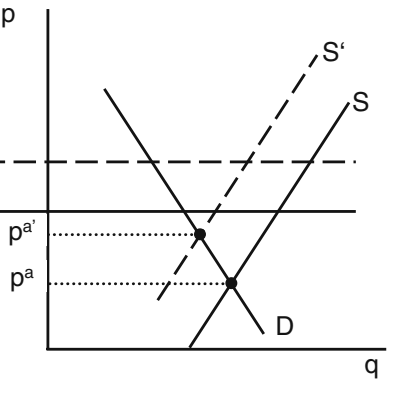

Fig. 4 Partial equilibrium two-region trade model. In the figure, $S$ is supply, $D$ is demand, $p$ refers to price, $q$ indicates volume, $X S$ is excess supply, and $X D$ is excess demand. The prime symbol indicates shifts in the parameters due to climate change 
of Fig. 4. A fundamental assumption is that no single country is large enough to set the world price of tart cherries, but instead price is determined by the intersection of world supply and demand. The lower cost country exports (depicted in the figure as excess supply [XS]), and the higher cost country imports (depicted as excess demand [XD]). The intersection of these two functions indicates the volume (q) and price $\left(\mathrm{p}^{\mathrm{w}}\right)$ of product that will be traded in the world market. Such a model is considered partial equilibrium as it assumes that the tart cherry sector of the economy is small enough so that changes within it have little or no impact on the rest of the economy and vice versa.

Consequences of climate change and its effects are incorporated in the model as changes in productivity or production of output. In Fig. 4 this is depicted as a shift in regional supply functions from $S$ to $S^{\prime}$. These adjustments then generate changes to excess supply $\left(\mathrm{XS}^{\prime}\right)$ and excess demand $\left(\mathrm{XD}^{\prime}\right)$ in the world economy, shifting trade patterns and economic outcomes. The new results for production and trade, when compared to those for a base period, can be further used to evaluate the new distribution of welfare, namely who gains and who loses in the economy as conditions change.

The trade model can be formulated for each future period under consideration. Output from the weather/climate dependency model feeds into the supply function, ${ }^{3}$ linking future climate change to production potential and supply (Fig. 4). For the example industry, microclimatic considerations, as mentioned previously, are particularly important in estimating supply, because variations in minimum temperature related to local landscape have large impacts on production. For the demand functions, it is important that assumptions underlying the projections of economic variables (e.g., income) are consistent with those of the emissions scenarios used to project climate change. An iterative approach can then be used to assess potential climate impacts. Initial model runs assume that growers do not change management practices (akin to some earlier assessments that included a "dumb farmer" scenario). The trade model is then run assuming that farmers can choose between multiple adaptation strategies (see Section 4); output from these runs provides an estimate of the capacity of markets to cope with climate change.

Within time slice factors for a selected production region are illustrated in Fig. 5 as an example. Individual production decisions drive regional supply possibilities (depicted on the right hand side of the figure). Within a time slice, demand and supply conditions remain fixed implying that consumer tastes and preferences as well as producer production structures are constant as are relative prices for substitute and complementary products. Differentiation among products (e.g., fruit from different cultivars or different products such as frozen versus fresh from the same cultivar) is permitted. To account for this differentiation, the initial one market (commodity) trade model can be extended to a multi-market (many commodities) trade model where different products are treated as different commodities.

Each production region has additional constraints that must be identified, such as infrastructure (e.g., production methods and technology), land use, institutions (e.g., trade practices), and local and national politics. These factors (shown in the middle box for Region 1) remain constant within the time slice. Another important

\footnotetext{
${ }^{3}$ Examples from the literature include Antle and Capalbo (2001) and Antle et al. (2007).
} 


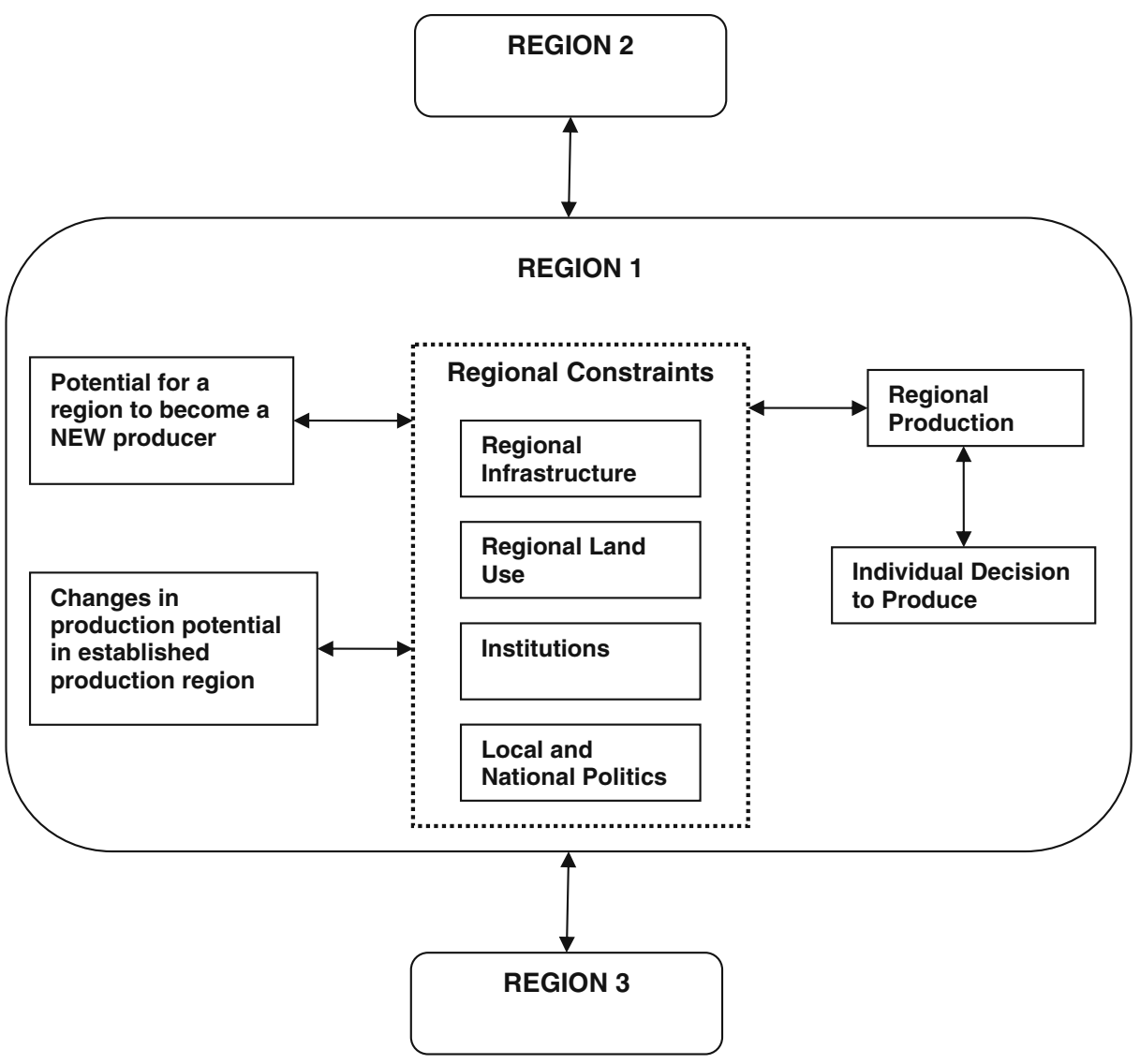

Fig. 5 Within and between time slice considerations for a production region

assumption is that the time slice be short enough so that while climate is changing the amount of change is relatively small that the focus within each time slice is the impact of climate variability on productivity. The boxes on the left hand side of the figure indicate flexibility between time slices as assumptions are relaxed.

\section{Projecting between time slices}

In the proposed framework, global and national changes in relevant macro-level variables need to be projected between time slices. In early impact assessments, future changes in macro-level variables such as GDP often were incorporated using simple "what if" scenarios. Possible, and hopefully plausible, changes in the variables were selected and the impact of these changes evaluated. Another approach has been to conduct a sensitivity analysis where the magnitude of key variables is changed by selected intervals within a prescribed range, and the sensitivity of the system to these changes is studied. More recently, scenarios of social-economic variables that evolve over time have been used in CCIAV studies (Carter et al. 2007). 
The majority of studies that have employed this approach have downscaled to the national or even subnational level broader-scale socio-economic scenarios that were used in the development of the greenhouse gas emissions scenarios from the Special Report of Emissions Scenarios (SRES) (Nakicenovic and Swart 2000). An important advantage of downscaling the SRES scenarios is that the macroeconomic variables complement the climate scenarios. In other words, both scenario suites are assuming similar evolution of the macroeconomic variables. The future development of new greenhouse gas emissions scenarios, along with the necessary background scenarios of social-economic variables, will likely lead to greater use of the later approach.

Since economic agents have been shown to adapt, another consideration for moving between time slices is that the set of variables over which an individual can make a choice must be identified and allowed to vary between time slices. Thus, additional variables become endogenous (within the decision-maker's choice set) in subsequent time slices although outcomes are not known with certainty. Decisions undertaken then reflect adaptation by agents, although since climate change is not fully perceived by agents, reaction by agents is imperfect.

Previous vulnerability assessments focused on "adaptation capacity" which refers to the ability or potential of a system to respond successfully to climate variability and change. However, the presence of adaptation capacity alone is not a sufficient condition for design and implementation of effective adaptation strategies (Adger et al. 2007). In our approach we divide the adaptation decision into two major components: technology constraints (indicating capacity or potential to adapt) and willingness by individuals and/or industries to adapt (Fig. 6). Adaptation can be achieved only through a combination of the two components (depicted by the intersection between the two circles).

Technology constraints play an important role in capacity. In the climate change literature, there has been growing recognition of the need to include technology adaptability to accurately measure impact (Kaiser et al. 1993; Darwin et al. 1995). For example, in the case of tart cherries the development of cold-resistant cultivars must occur before individuals can undertake cultivar change as an adaptation strategy. Constraints are different for each region as each has a different production environment and institutional capacity, which means there is the potential for regional differentials in adaptations as well as baseline conditions.

Fig. 6 Components of adaptation

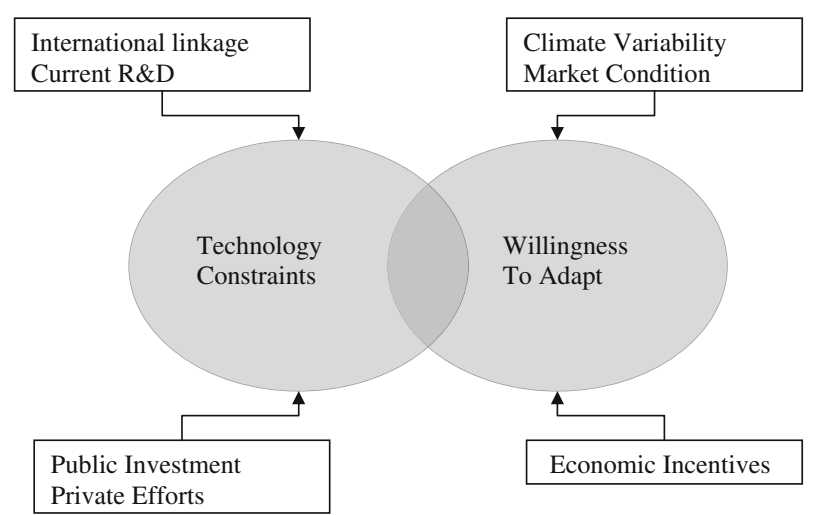


Table 1 Role of adaptation decision variables for the tart cherry industry over time

\begin{tabular}{lll}
\hline Time slices & $\begin{array}{l}\text { Exogenous to the } \\
\text { decision-maker }\end{array}$ & $\begin{array}{l}\text { Endogenous to the } \\
\text { decision-maker }\end{array}$ \\
\hline $\begin{array}{l}\text { Baseline (e.g., 2000-2010); } \\
\text { no adaptation }\end{array}$ & $\begin{array}{l}\text { Cultivar } \\
\text { Input use } \\
\text { Infrastructure } \\
\text { (small and large) }\end{array}$ & None \\
& Orchard design & \\
Time slice \#1 (e.g., 2010-2030); & Cultivar & \\
minimum adaptation & Orchard design & Management adjustment \\
& Infrastructure & Input use adjustment \\
& (small and large) & Infrastructure (small): \\
Time slice \#2 (e.g., 2040-2060); & Cultivar & Origation, frost protection \\
quasi-adaptation & Infrastructure (large) & Farming practice: mulching \\
& & Infrastructure (small): \\
& & irrigation, frost protection \\
Time slice \#3 (e.g., 2070-2090); & None & Land use conversion \\
maximum adaptation & & New cultivars \\
& & Infrastructure (large)
\end{tabular}

Another necessary condition for adaptation is captured through willingness to adapt. To invest in an adaptation, individuals must consider it to be potentially profitable. ${ }^{4}$ Individuals may be reluctant to adapt because of the additional uncertainty surrounding future climate change as well as uncertainty associated with market conditions. The challenge of evaluating potential profitability can make individuals reluctant to make an adaptation decision, especially if the decision is not easily reversible.

We can conceptualize adaptation options in the example industry for a specific region. A baseline (for example, 2000-2010) can be considered a current period given technology and production practices. As time progresses, three stages of adaptation can be assumed: minimum adaptation (in the nearest time slice), quasi-adaptation (in a mid-range time slice) and maximum adaptation (in a long-range time slice; Table 1). For any of the time slices, the mix of adaptation strategies can differ across regions. In our example industry, a reasonable choice for the nearest time period, or minimal adaptation stage, would be 2010-2030 based on the approximate 25to 30-year economic life of a tart cherry tree. In it, choices over variable input use (e.g. labor, frost protection, irrigation, fertilizer, or pesticides) in response to climate change are within grower control. Additional variables such as orchard design and small infrastructure are endogenous in the quasi-adaptation stage (e.g., 2040-2060). In the long-run (e.g., 2070-2090), we can assume all decision variables are within the grower's decision set and choices can be made not only over the set of variables already indicated above, but also over crop or cultivar selection and other large-scale investments. Similar to the stages of adaptation, the trade model can incorporate different price responsiveness in subsequent time slices. In the short run grower

\footnotetext{
${ }^{4}$ Methods often used to implement profitability are net present value and real options. See Schwartz and Trigeorigis (2001) for more information.
} 
response to price changes is assumed to be small, while in the long run when growers have more options within their control response to price increases (Koester 2005).

\section{Uncertainty analysis and transferability intercomparisons}

CCIAV assessments are "particularly susceptible to ballooning uncertainties because of limits of prediction" (Carter et al. 2007, p. 141). However, estimating, characterizing, and communicating uncertainty are challenging undertakings, in part because of the many possible uncertainty sources (e.g., Ahmad et al. 2001), but also because of disciplinary differences in terminology and emphasis (Montanari 2007). Although alternative classifications are possible (e.g., Walker et al. 2003), we differentiate between two broad categories of uncertainty: (1) calibration error such as error introduced by the short period of observations available to calibrate a model, and (2) model structure error arising from how a model is formulated such as what terms are included. Whereas climate change assessments often consider calibration error, at least for a subset of the models used in the assessment, model structural error is typically only considered for the climate component. As an example, Lobell et al. (2008) fed a suite of climate scenarios, which reflected differences in the structural form of climate models, into statistically-derived crop models for different crops and regions. The uncertainty evaluation for the crop models was limited to a sensitivity analysis of model parameters, or, in other words, an evaluation of calibration error. Consequently, the uncertainty surrounding the dependency of the system (i.e., crop production) to climate change was not considered.

We argue that for assessments of international market systems the "metauncertainty" surrounding the entire assessment framework must be considered in addition to the calibration error of the individual models or the structural error associated with an individual component. By meta-uncertainty, we refer to the aggregated uncertainty due to differences in functional form, or structure, of the suite of linked models. The literatures on climate modeling and integrated assessment models provide possible approaches to evaluating meta-uncertainty. A standard approach for displaying uncertainty surrounding projected climate change is to employ an ensemble of projections from different climate models. The focus is on the uncertainty associated with the "final" model output (e.g., projected change in global temperature) rather than an appraisal of the uncertainty for the different model subcomponents (e.g., convection schemes) or parameterizations. In contrast, the DIALOGUE integrated assessment model (Visser et al. 2000) used a parallel modeling approach, whereby three or more equivalent models were implemented for each module or step in a modeling system, resulting in a large number of individual model "chains" and hence projections. While this approach also provides an estimate of what the DIALOGUE developers refer to as "maximum uncertainty range", the relative contribution of the different modules to the maximum uncertainty can additionally be evaluated. Borrowing from these approaches, an ensemble of outcomes from the linked model sequence described above can be constructed from the multiple model chains resulting from the use of parallel models for each of the major components of the assessment. This meta-uncertainty approach, in our opinion, is in line with what industry stakeholders would find most useful, as the emphasis is on the uncertainty of the final outcomes rather than on individual 
components of the assessment. Furthermore, following the arguments of Refsgaard et al. (2006), uncertainty in model structure is a greater concern than calibration uncertainty in situations, such as CCIAV assessments, when models are used to extrapolate beyond the range of observed conditions.

For the tart cherry example, potential outcomes of the assessment include price, quantity of product produced, and trade amounts for the different production regions. For each time slice, ensembles can be developed for these outcomes that reflect different combinations of alternative model structures. For the climate component, structural differences in GCMs, RCMs, and downscaling procedures can be represented by a suite of climate scenarios. Similarly, multiple characterizations of the weather/climate dependency model can be used to represent structural uncertainty surrounding this component of the assessment. Two defendable characterizations are a tart cherry yield model developed from the production function perspective versus one developed using a hedonic approach. Differences in structural form for the economic components of the assessment could include versions of a trade model that consider different market characteristics, such as product differentiation, different representations of the supply functions, and the inclusion of product stocks. A key consideration is that the parallel (i.e., alternative) models sample, as much as possible, "the relevant space of plausible conceptual models" (Refsgaard et al. 2006, p. 1586).

A climate change assessment for international market systems also allows for what Takle et al. (2007) refer to as "transferability intercomparisons." Models developed for one region may not be transferable to another region, as the parameters of the functions and models may have been specifically "tuned" to phenomena unique to a region. Model transferability is certainly a concern for the example industry. As discussed earlier, a yield function derived for the tart cherry growing regions in northwestern and west-central Michigan did not perform as well in southwestern Michigan. Discrepancies in model performance can also be expected when applying yield functions or phenology models derived for North American production regions to European regions, and vice versa. Similarly, differences in the performance of RCMs and empirical downscaling functions between regions are anticipated. Tastes, preferences and employment alternatives vary among regions, so response to economic change will also vary.

While poor performance when models are applied out-of-sample is a challenge, an industry-wide assessment provides an opportunity for comparing multiple models in multiple regions, which, in contrast to typical model intercomparisons that are limited to either applying multiple models to a single region or a single model to multiple regions, is more likely to expose the limits of current models and model parameterizations and contribute to global model improvement (Takle et al. 2007). Furthermore, more confidence can be placed in the transferability of models to future time slices if, based on comparisons for current and historical periods, the models perform well in multiple spatial domains that experience a wide range of conditions, some of which might be reflective of the future expectations for a specific region. Additionally, transferability comparisons lead to more informed use and interpretation of current models, such as applying randomization procedures (e.g., Monte Carlo and Gaussian quadrature methods) to estimate the sensitivity of outcomes to parameters considered to be weak in out-of-sample regions (Artavia et al. 2009), and more generally to model improvements. 


\section{Stakeholder engagement}

A crucial component of CCIAV assessments is the incorporation of stakeholder knowledge and perspectives. In the context of international market systems, stakeholders can broadly be thought of as individuals or organizations who either participate in the industry or who are directly or indirectly affected by actions and policies related to the industry. Kloprogge and van der Sluijs (2006, p. 365) state that "stakeholder reasoning, observation and imagination are not bounded by scientific rationality" and argue that the "extended facts" that stakeholders contribute to an assessment enhance the quality of the assessment, lead to more effective means for dealing with uncertainty, and "legitimize" the assessment particularly in the eyes of other stakeholders. Furthermore, stakeholder involvement is thought to lead to greater utility of the assessment outcomes (Romsdahl and Pyke 2009), provide a sounder basis for decision making (Moser 2009), and ensure that important components or concerns are not overlooked (Kloprogge and van der Sluijs 2006). Oftentimes stakeholders can provide access to additional or alternative data sources and provide insights on data quality and local conditions (Kloprogge and van der Sluijs 2006; Moser 2009). In addition, insights from stakeholders are essential for identifying adaptation options and evaluating feasibility. Stakeholder input is also critical when evaluating the effectiveness of an assessment (Moser 2009; Romsdahl and Pyke 2009).

In spite of a general consensus that stakeholder engagement is essential, participation of stakeholders in CCIAV assessments to date has been limited (Toth and Hizsnyik 2008), or, if considered, has been relatively ad hoc and unplanned (Carney et al. 2009). This limited engagement in part reflects the substantial resources needed to effectively engage stakeholders in CCIAV assessments. Kloprogge and van der Sluijs (2006) differentiate between active and passive stakeholder involvement. For active involvement, stakeholders directly interact with the assessment organizers and with other stakeholders and contribute to the formation of the assessment outcomes and their interpretation. Passive involvement refers to the situations when assessment organizers incorporate viewpoints and knowledge that they have elicited from stakeholders but do not directly involve stakeholders in the assessment process. These distinctions are important, as generally more resources are required for active stakeholder involvement, whereas misinterpreting and/or incorrectly incorporating stakeholder knowledge and perspectives is more likely for passive involvement (Kloprogge and van der Sluijs 2006).

Ideally, an industry-wide climate change assessment would be initiated by stakeholders or jointly by scientists and stakeholders who would co-shape and co-produce the assessment. Stakeholder involvement, however, will be a much greater challenge for assessments of international market systems compared to a more typical local/ regional climate change impact assessment. The sheer number of stakeholders for a global industry with multiple production regions is daunting, and the capacity and opportunity for stakeholders to become involved will likely vary between production regions. Careful attention is therefore needed to ensure that the stakeholder input is representative of the diverse production regions. Active stakeholder involvement is also complicated by language barriers and cultural differences, as is the delivery of the assessment outcomes to stakeholders for their use in decision making. Given the large number of stakeholders, industry advocacy groups who represent multiple 
interests (e.g., producers, processors, distributors) and technical experts who have developed trusted relationships with stakeholders (Romsdahl and Pyke 2009) and can accurately reflect stakeholder knowledge and perspectives are likely to play important roles in the assessment process for international market systems.

The example industry highlights the potential contribution of stakeholders to an industry-wide climate change assessment. In fact, our interest in assessment strategies for international market systems arose from concerns expressed by tart cherry growers. Thus these stakeholders have played a pivotal role in identifying and framing the initial problem of industry-wide assessments. Prior to 2002, the United States imported only a small (typically $<1,000 \mathrm{~kg}$ ) portion of domestic tart cherry consumption, primarily from Canada (Aguilar 2006). A short crop in 2002 due to an unprecedented severe spring freeze in the primary tart cherry production areas in northwestern Michigan opened the door to imports from Europe, particularly from Poland. In listening sessions as part of the previously-mentioned Pileus Project, growers in Michigan emphasized that an evaluation of how climate change might impact their industry required an assessment of potential changes in phenology and yield in both Michigan and Poland (now considered a major competitor). Similarly, Polish growers have experienced lower yields in several recent years due to freeze events, and they have expressed to us their concerns regarding the impact of new production regions in Europe and elsewhere on demand for their product, particularly if the new production regions do not have as large a risk for damaging spring freeze events. Furthermore, recent reductions in tart cherry yield due to hail damage and prolonged drought have increased awareness among Hungarian producers of potential impacts of climate change on scales from local to global. These conversations with growers in different parts of the world highlight that climate change assessments for global industries must extend beyond the local or regional scale to be useful for industry decision making.

The development of phenology and yield models for the Michigan tart cherry production regions (Zavalloni et al. 2006a, 2008) further highlights the potential contributions of industry stakeholders. Stakeholders helped identify important predictors, made available orchard level measurements of phenology, and provided a perspective on historical yield variations and on landscape-induced spatial variations in yield. The Pileus Project also was able to capitalize on-long term relationships between industry stakeholders and horticultural extension specialists, illustrating the potential contribution of trusted technical experts. In addition, a national marketing organization and task force provided an effective means for reaching a large number of stakeholders from growers to distributors.

\section{Strengths and limitations of the proposed framework}

A strength of the framework proposed here is that it is multi-regional in extent allowing for the assessment of a market system with international scope. The framework also is tractable in that it allows for dynamic modeling where feasible and for other variables and processes uses a static, fixed time slice approach. In addition, the framework allows for adaptation with adaptation occurring between time slices but within time slice modeling suggesting the types of adaptation that may take place. The framework also considers the sensitivity of an industry to climate variability 
and extremes. Additionally, the use of a linked approach for the within time slice modeling can facilitate the incorporation of uncertainty surrounding the separate system components (Yohe 1990; Visser et al. 2000). The use of the separate linked models also allows for complex models of the individual components, when available, to be used in the assessment process.

Any approach to modeling change over long periods of time has limitations. The approach we outline here is no exception. A fundamental limitation is that the framework does not allow for feedbacks between system components except in a static manner. In this aspect, the framework is inferior to an integrated assessment model that explicitly models cross component feedbacks. In addition, because of the complexity of the system, it is difficult to consider within the framework the full vulnerability of the industry to climate change. Although other agents of change, such as land use change, which affect an industry were not explicitly discussed above, they could be incorporated into the framework as between time slice changes. However, identifying all possible change agents is unlikely. In addition, this framework, along with any other, suffers from incomplete knowledge of the different components, making the development of individual models and their linkage to other models difficult.

Another consideration is that the proposed framework does not include a modeling component to quantitatively identify potential new production regions. Instead, expert judgment is used to select new production areas and to introduce them into the assessment for a future time slice. This is in contrast to several sectoral (i.e., multiple industry) analyses, such as the study by Fischer et al. (2005) for the agricultural sector which used global soil information and coarse-scale projections of basic climate variables (monthly temperature and precipitation) to identify potential new growing regions for cereal grains. The advantage of using expert judgment is that the selection of new production sites is a complex decision that goes beyond favorable climatic conditions, and other factors such as proximity to related industries, local skill sets, political constraints, and cultural factors must be taken into consideration. A disadvantage is that some potential production sites may be overlooked, as current production patterns may unduly influence the selection of alternative locations to include in the future time slices when expert judgment is used.

Implementing the framework can be challenging, as discussed above. One challenge not discussed earlier is that climate change assessments are interdisciplinary undertakings and the perspective on time and change may differ among disciplines. For example, climate scientists often take a long-term view of change, focusing on climate change that may occur 50 to 100 years in the future. Short-term change is much less important, because in the short term it is difficult to gauge change from variability. On the other hand, the temporal perspective of change for economists tends to be shorter, reflecting the time horizon of public and private investor decisions. For the most part, the aggregated decisions by individual producers are being modeled, and producers have shorter time horizons than those associated with longer-term climate change.

In addition, numerous factors beyond climate change influence investor decisions, such as, for the example industry, changing consumer preferences that increase or decrease the demand for tart cherry products, uneven changes in wealth effects influencing patterns of supply and mix of goods demanded, political actions in response to environmental or trade concerns that lead to changes in subsidies, within 
industry technical improvements that reduce the amount of time before current investments yield dividends, and technological change outside of the industry that have unanticipated spillover effects. These factors may make investments unappealing to the individual producer due to the long payback period associated with capital investments, and consequently, producers may prefer to diversify investments to a greater degree than the proposed framework would predict.

In spite of the limitations discussed above, the proposed expanded assessment framework provides a strategy and starting point for undertaking climate change impact assessments of industry-specific international market systems. The necessary next steps are to apply the framework to a variety of industries to evaluate its usefulness and make modifications as necessary.

\section{Concluding remarks}

In an editorial reflecting on the Working Group II report of the IPCC Fourth Assessment, Liverman (2007) remarked that "there are too many gaps in geographical and sub-sectoral coverage, ... too little in the way of economic analysis, ... and too many case studies undertaken outside frameworks that permit aggregation, comparison or general insights." She concluded that, as a result, progress since the IPCC Third Assessment Report on understanding impacts, adaptation and vulnerability to climate change has been limited. We concur with Liverman that sub-sectoral assessments, including assessments of international market systems, have been woefully neglected and that much work is needed in this area to better appreciate the potential impacts of climate change.

One reason that sub-sectoral assessments of international market systems are infrequently undertaken is the challenging nature of these types of analyses. In contrast to global sectoral assessments (e.g., global agriculture), which often can justifiably make a number of simplifying assumptions in the relationship between productivity and climate, assessments for specific industries need more explicit, detailed representations of weather/climate dependency and finer-scale, comprehensive scenarios of future climate. In addition, they need to include stakeholder decision making more explicitly than in larger-scale sectoral assessments. These types of analyses also are hindered by the lack of a framework for undertaking and organizing the assessments. Additionally, methods for incorporating economic factors such as international trade are still poorly developed.

In this paper, we provided a conceptual framework for climate change impact assessments for international market systems that involve long-term investments and discussed its implementation in terms of an example industry. The framework is a hybrid of dynamic and static modeling. Dynamic modeling is used for those system components for which temporally continuous modeling is possible and fixed time slices for other system components where it can be assumed that underlying assumptions are held constant within time slices but allowed to vary between time slices. Unlike most other sub-sectoral assessments, international trade is explicitly modeled in the proposed framework. The proposed framework hopefully will act as a catalyst for further discussion and thought about possible approaches to climate 
change assessments for industries with production regions that are dispersed globally and that are vulnerable to climate variations and change, especially climate extremes.

Acknowledgements This work was partially supported by NSF grant SES 0622954 and by an Environmental Research Initiative Grant from Michigan State University. We thank the stakeholders of the international tart cherry industry with whom we have worked over the years for their invaluable input, feedback, and encouragement. Also, our thanks to the anonymous reviewers for their helpful comments.

Open Access This article is distributed under the terms of the Creative Commons Attribution Noncommercial License which permits any noncommercial use, distribution, and reproduction in any medium, provided the original author(s) and source are credited.

\section{References}

Adger WN, Agrawala S, Mirza MMQ, Conde C, O'Brien K, Pulhin J, Pulwarty R, Smit B, Takahashi K (2007) Assessment of adaptation practices, options, constraints and capacity. In: Parry ML, Canziani OF, Palutikof JP, van der Linden PJ, Hanson CE (eds) Climate change 2007: impacts, adaptation and vulnerability. Contribution of Working Group II to the Fourth Assessment Report of the Intergovernmental Panel on Climate Change. Cambridge University Press, Cambridge, pp 717-743

Agasse A (2007) Climate change could play havoc with oil prices. Energy Daily. Available at http:// www.energy-daily.com/reports/Climate_Change_Could_Play_Havoc_With_Oil_Prices_999.html

Aguilar CA (2006) Trade analysis of specific agri-food commodities using a gravity model. M.A. thesis, Department of Agricultural Economics, Michigan State University

Ahmad Q, Warrick RA, Downing TE, Nishioka S, Parikh KS, Parmesan C, Schneider SH, Toth F, Yohe G (2001) Methods and tools. In: McCarthy JJ, Canziani OF, Leary NA, Dokken DJ, White KS (eds) Climate change 2001: impacts, adaptation, and vulnerability. Contribution of Working Group II to the Third Assessment Report of the Intergovernmental Panel on Climate Change. Cambridge University Press, Cambridge, UK, pp 105-144

Anania G (2001) Modeling agricultural trade liberalization and its implications for the European Union. INEA Working Paper No. 12

Andresen JA, Alagarswamy G, Ritchie JT, Rotz CA, LeBaron AW (2001) Assessment of the impact of weather on maize, soybean, and alfalfa production in the Upper Great Lakes Region of the United States, 1895-1996. Agron J 93:1059-1070

Antle JM, Capalbo SM (2001) Econometric-process models for integrated assessment of agricultural production systems. Am J Agric Econ 83(2):389-401

Antle JM, Capalbo SM, Paustian KH, Ali MK (2007) Estimating the economic potential for agricultural soil carbon sequestration in the central United States using an aggregate econometricprocess simulation model. Clim Change 80(1-2):145-171

Arnell NW, Hudson DA, Jones R (2005) Climate change scenarios from a regional climate model: estimating change in runoff in Southern Africa. J Geophys Res-Atmos 108(D16):4519

Artavia M, Grethe H, Möller T, Zimmermann G (2009) Correlated order three Gaussian quadratures in stochastic simulation modelling. Paper presented at the Twelfth Annual Conference on Global Economic Analysis, Santiago, Chile, 10-12 June

Becken S, Hay JE (2007) Tourism and climate change: risks and opportunities. Channel View, Clevedon

Brassard JP, Singh B (2007) Effects of climate change and $\mathrm{CO}_{2}$ increase on potential agricultural production in Southern Quebec, Canada. Clim Res 34:105-117

Carney S, Whitmarsh L, Nicholson-Cole SA, Shackley S (2009) A dynamic typology for stakeholder engagement within climate change research. Tyndall Center for Climate Change Research, Working Paper 128. Available at http://www.tyndall.ac.uk/publications/working_papers/ twp128.pdf

Carter TR, Jones RN, Lu X, Bhadwal S, Conde C, Mearns LO, O'Neill BC, Rounsevell MDA, Zurek MB (2007) New assessment methods and the characterisation of future conditions. In: Parry ML, Canziani OF, Palutikof JP, van der Linden PJ, Hanson CE (eds) Climate change 
2007: impacts, adaptation and vulnerability. Contribution of Working Group II to the Fourth Assessment Report of the Intergovernmental Panel on Climate Change. Cambridge University Press, Cambridge, pp 133-171

Darwin RF, Tsigas M, Lewandrowski J, Raneses A (1995) World agriculture and climate change: economic adaptations. Agricultural Economic Report Number 703, United States Department of Agriculture, Economic Research Service, Washington, DC

Deschênes O, Greenstone, M (2007) The economic impacts of climate change: evidence from agricultural output and random fluctuations in weather. Am Econ Rev 97:354-385

Eitzinger J, Stastna M, Zalud Z, Dubrovsky M (2003) A simulation study of the effect of soil water balance and water stress on winter wheat production under different climate change scenarios. Agr Water Manag 61:195-217

Fischer G, Shah M, Tubiello FN, van Velhuizen H (2005) Socio-economic and climate change impacts on agriculture: an integrated assessment, 1990-2080. Philos Trans R Soc Lond B 360:29672083

Ford JD, Pearce T, Prno J, Duerden F, Berrang Ford L, Beaumier M, Smith T (2009) Perceptions of climate change risks in primary resource use industries: a survey of the Canadian mining sector. Reg Environ Change. doi:10.1007/s10113-009-0094-8

Francois J, Reinert K (1997) Applied methods for trade policy analysis: a handbook. Cambridge University Press, Cambridge

Füssel H-M (2007) Adaptation planning for climate change: concepts, assessment approaches, and key lessons. Sustain Sci 2:265-275

Gijsman AJ, Hoogenboom G, Parton WJ, Kerridge PC (2002) Modifying DSSAT crop models for low-input agricultural systems using a soil organic matter-residue module from CENTURY. Agron J 94(3):462-474

Hulme M, Jenkins G, Lu X, Turnpenny JR, Mitchell TD, Jones RG, Lowe J, Murphy JM, Hassell D, Boorman P, McDonald R, Hill S (2002) Climate change scenarios for the United Kingdom: the UKCIP02 Scientific Report. Technical Report, Tyndall Centre for Climate Change Research, Norwich

IPCC (2001) Glossary of terms. In: McCarthy JJ, Canziani OF, Leary NA, Dokken DJ, White KS (eds) Climate change 2001: impacts, adaptation and vulnerability. Cambridge University Press, Cambridge

Jechlitschka K, Kirschke D, Schwarz G (2007) Microeconomics using Excel. Routledge, New York

Jones JW, Hoogenboom G, Porter CH, Boote KJ, Batchelor WD, Hunt LA, Wilkens PW, Singh U, Gijsman AJ, Ritchie JT (2003) DSSAT cropping system model. Eur J Agron 18:235-265

Kaiser HM, Riha SJ, Wilks DS, Rossiter DG, Sampath R (1993) A farm-level analysis of economic and agronomic impacts of global warming. Am J Agric Econ 75:387-398

Kloprogge P, van der Sluijs JP (2006) The inclusion of stakeholder knowledge and perspectives in integrated assessment of climate change. Clim Change 75:359-389

Koester U (2005) Grundzüge der landwirtschftlichen marklehre. Vahlen, Munich

Leung LR, Yuan Q, Bian X, Washington W, Han J, Roads JO (2004) Mid-century ensemble regional climate change scenarios for the western United States. Clim Change 65:75-113

Liverman D (2007) Assessing impacts, adaptation and vulnerability: reflections on the Working Group II report of the International Panel on Climate Change. Glob Environ Change 18: 4-7

Lobell DB, Field CB, Nicholas-Cahill K, Bonfils C (2006) Impacts of future climate change on California perennial crop yields: model projections with climate and crop uncertainties. Agric For Meteorol 141:208-218

Lobell DB, Burke M, Tebaldi C, Mastrandrea M, Falcon W, Naylor R (2008) Prioritizing climate change adaptation needs for food security in 2030. Science 319:607-610

MacCracken MC, Barron EJ, Easterling DR, Felzer BS, Karl TR (2003) Climate change scenarios for the U.S. National Assessment. Bull Am Meteorol Soc 84:1711-1723

McBoyle G, Scott D, Jones B (2007) Climate change and the future of snowmobiling in nonmountainous regions of Canada. Manag Leis 12:237-250

Mendelsohn R, Nordhaus WD, Shaw D (1994) The impact of global warming on agriculture: a Ricardian analysis. Am Econ Rev 84:753-771

Mesinger F, DiMego G, Kalnay E, Mitchell K, Shafran PC, Ebisuzaki W, Joviæ D, Woollen J, Rogers E, Berbery EH, Ek MB, Fan Y, Grumbine R, Higgins W, Li H, Lin Y, Manikin G, Parrish D, Shi W (2006) North American regional reanalysis. Bull Am Meteorol Soc 87: 343-360 
Montanari A (2007) What do we mean by 'uncertainty'? The need for a consistent wording about uncertainty assessment in hydrology. Hydrol Process 21:841-845

Moser S (2009) Making a difference on the ground: the challenge of demonstrating the effectiveness of decision support. Clim Change 95:11-21

Nakicenovic N, Swart R (eds) (2000) Special report on emissions scenarios. Cambridge University Press, Cambridge, UK

Nordhaus WD (1994) Managing the global commons: the economics of climate change. MIT, Cambridge

Refsgaard JC, van der Sluijs JP, Brown J, van der Keur P (2006) A framework for dealing with uncertainty due to model structure error. Adv Water Resour 29:1586-1597

Reilly J, Hohman N (1993) Climate change and agriculture: the role of international trade. Am Econ Rev 83:306-312

Romsdahl RJ, Pyke CR (2009) What does decision support mean to the climate change research community? Clim Change 95:1-10

Schneider S, Lane J (2005) Integrated assessment modeling of global climate change: much has been learned-still a long and bumpy road ahead. Integr Assess 5:41-75

Schlenker W, Hanemann WM, Fisher AC (2005) Will U.S. agriculture really benefit from global warming? Accounting for irrigation in the hedonic approach. Am Econ Rev 95:395-406

Schlenker W, Hanemann WM, Fisher AC (2007) Water availability, degree days and the potential impact of climate change on irrigated agriculture in California. Clim Change 81:19-38

Schwartz ES, Trigeorigis L (eds) (2001) Real options and investment under uncertainty: classical reading and recent contributions. MIT, Cambridge

Scott D, McBoyle G, Mills B, Minogue A (2006) Climate change and the sustainability of the skibased tourism in eastern North America: a reassessment. J Sustain Tour 14(4):376-398

Sohngen B, Mendelsohn R, Sedjo R (2001) A global model of climate change impacts on timber markets. J Agric Resour Econ 26(2):326-343

Takle ES, Roads J Rockel B, Gutowksi WJ Jr, Arritt RW, Meinke I, Jones CG, Zadra A (2007) Transferability intercomparison. An opportunity for new insight on the global water cycle and energy balance. Bull Am Meteorol Soc 88:375-384

Toth FL, Hizsnyik E (2008) Managing the inconceivable: participatory assessments of impacts and responses to extreme climate change. Clim Change 91:81-101

Tsvetsinskaya EA, Mearns LO, Mavromatis T, Gao W, McDaniel L, Downton MW (2003) The effect of spatial scale of climatic change scenarios on simulated maize, winter wheat, and rice production in the southeastern United States. Clim Change 60:37-71

Van Asselt MBA, Rotmans J (2002) Uncertainty in integrated assessment modeling. Clim Change 54:75-105

Van Tongeren F, Van Meijl H (1999) Review of applied models of international trade in agriculture and related resource and environmental modelling. LEI Report 5.99.11

Visser H, Folkert JM, Hoekstra J, De Wolff JJ (2000) Identifying key sources of uncertainty in climate change projections. Clim Change 45:421-457

von Witzke H, Lotze-Campen H, Moeller T (2008) Climate change in the German wheat economy: a methodological framework. Working Paper, Institute of Agricultural Economics, Humboldt University of Berlin

Walker WE, Harremoës P, Rotmans J, van der Sluijs JP, van Asselt MBA, Janssen P, Krayer von Krauss MP (2003) Defining uncertainty. A conceptual model for uncertainty management in model-based decision support. Integr Assess 4:5-17

Wilby RL, Charles SP, Zorita E, Timbal B, Whetton P, Mearns LO (2004) Guidelines for use of climate scenarios developed from statistical downscaling methods. Available from the DDC of IPCC TGCIA, $27 \mathrm{pp}$

Winkler JA, Andresen JA, Guentchev G, Kriegel RD (2002) Possible impacts of projected temperature change on commercial fruit production in the Great Lakes region. J Great Lakes Res 28:608-642

Winkler JA, Bisanz J, Guentchev G, Piromsopa K, van Ravensway J, Prawiranata H, Torre R, Min HK, Clark J (2010) The development and communication of an ensemble of local-scale climate scenarios: an example from the Pileus Project. In: Dietz T, Bidwell D (ed) Proceedings of the international symposium on climate change in the Great Lakes region: decision making under uncertainty. Michigan State University Press, East Lansing, MI (in press)

Yohe GW (1990) Imbedding dynamic responses with imperfect information into static portraits of the regional impact of climate change. Paper presented at the International Work- 
shop on the National Resource and Economic Implications of Global Climate Change, Interlaken Switzerland, November 5-9, 1990. Available at http:/www.osti.gov/energycitations/ servlets/purl/6147467-tHoU3E/6147467.PDF

Yohe G, Tirpak D (2008) A research agenda to improve economic estimates of the benefits of climate change policies. Integr Assess 8:1-17

Zavalloni C, Andresen JA, Flore JA (2006a) Phenological models of flower bud stages and fruit growth of 'Montmorency' sour cherry based on growing degree-day accumulation. J Am Soc Hortic Sci 131:601-607

Zavalloni C, Andresen JA, Winkler JA, Flore JA, Black JR, Beedy TL (2006b) The Pileus Project: climatic impacts on sour cherry production in the Great Lakes Region in past and projected future time frames. Acta Hortic 707:101-108

Zavalloni C, Andresen JA, Black JR, Winkler JA, Guentchev G, Piromsopa K, Pollyea A, Bisanz JM (2008) A preliminary analysis of the impacts of past and projected future climate on sour cherry production in the Great Lakes Region of the USA. Acta Hortic 803:123-130 